\title{
BATATA CON SANIDAD CONTROLADA MODELO PRODUCTIVO PARA LA PROVINCIA DE CORRIENTES
} Health-controlled sweet potato. Productive model for Corrientes province

\author{
González, César A. ${ }^{1}$; Chroniuk, Franco M. ${ }^{1}$; Mambrin, Augusto G. ${ }^{1}$; Taffarel, Oscar A. ${ }^{1}$; \\ Pletsch, Mariela C. ${ }^{2 ; 3}$. \\ ${ }^{1}$ Centro Tecnológico de Producción. ${ }^{2}$ Dirección de Producción Vegetal. ${ }^{3}$ Ministerio de Producción. \\ Ruta Nacional $\mathrm{N}^{\circ} 12 \mathrm{~km} 1032$ \\ cesaragrogonzalez@gmail.com marielapletsch@yahoo.com.ar
}

\section{RESUMEN}

Las regiones productoras de batata del país han sufrido disminución de la superficie plantada, con mermas de rendimientos de las principales variedades comerciales. Esto se atribuye a enfermedades causadas por la sinergia de al menos cinco virus de difícil detección, incluso a través de métodos serológicos/moleculares. La infección durante el ciclo de cultivo se produce a través de insectos vectores: pulgones y moscas blancas. Los efectos de estas enfermedades pueden mitigarse con el uso de material de propagación agámica de sanidad controlada, multiplicado a partir de semilla básica o fundación provista por el Instituto de Patología Vegetal (IPAVE), Córdoba, que se obtiene a su vez, mediante micropropagación in vitro de meristemas y termoterapia. La multiplicación masiva se realiza a través de viveros en las diferentes zonas productoras del país. En 2017 el Ministerio de Producción de Corrientes creó el programa Multiplicación de Batata con Sanidad Controlada, mediante el cual puso en funcionamiento el Vivero Hortícola del Centro Tecnológico de Producción, con diferentes cultivares (cvs). La macropropagación se realiza en invernadero cumpliendo con el protocolo sanitario establecido. La producción obtenida se destina principalmente a productores comerciales beneficiarios del Proyecto, que llevan adelante sus propios "núcleos semilleros", donde se plantan los esquejes saneados y a partir de los cuales se obtiene material de propagación para lotes comerciales. Estos núcleos se encuentran protegidos con malla anti-insecto. Con lo que se pretende bajar la presión de inóculo, recuperar superficie y calidad de producción.

Palabras clave: Boniato - Camote - Guías - Virus- Microtúnel- Semillero.

\begin{abstract}
Sweet potato-growing regions in the country have suffered a decrease in their planted area, with declines in the yields of the main commercial varieties. The main cause of this is attributed to diseases caused by the synergy of at least five viruses that are difficult to detect, even through serological/ molecular methods. Infection within the crop cycle occurs by insect vectors: aphids and white flies. In order to mitigate the effects of these diseases, controlled-health agamic propagation material should be used, multiplied from basic seed or foundation provided by the Institute of Plant Pathology (IPAVE), Cordoba, which was obtained, in turn, from in vitro micropropagation of meristems and thermotherapy. The massive multiplication is carried out through greenhouses at different producing areas of the country. In 2017, the Ministry of Production of Corrientes created the program Sweet Potato Multiplication with Controlled Health, which set in motion the Horticultural Greenhouse of the Technological Center of Production, with different cultivars (cvs). The macro propagation is carried out in a greenhouse that complies with the established sanitary protocol. The production obtained is mainly destined to commercial producers who are beneficiaries of the Program. "Seedbeds" are built, where healthy cuttings are planted and from which propagation material for commercial lots is obtained. These nuclei are protected with anti-insect netting.This is intended to lower inoculum pressure, recover surface area and production quality.
\end{abstract}

Key words: Sweet potato- Vines cuttings- Storage roots- Virus- Screen house.

Recibido: 16/jun/2020. Aceptado: 10/ago/2020 


\section{INTRODUCCIÓN}

La batata [Ipomoea batatas (L.) Lam.] es una especie herbácea y perenne, sin embargo, es cultivada como una planta anual utilizando raíces reservantes y esquejes (guías) para su propagación vegetativa. Pertenece a la familia de las Convolvuláceas (Huamán, 1992). A nivel global se cultiva en los cinco continentes. Dentro de los cultivos destinados a la alimentación se ubica en el séptimo lugar y en el tercero de los que tiene órganos comerciales subterráneos luego de la papa y la mandioca (Loebenstein et al., 2009). En las últimas dos décadas la batata en el mundo ha experimentado una disminución de la superficie cosechada FAOSTAT, (2019). La principal causa de esto se atribuye a enfermedades causadas por virus. En algunos casos la sinergia de los mismos produce enfermedades aún más graves y de difícil detección, incluso a través de métodos serológicos/ moleculares (DiFeo, 2015; Fajardo et al. 2007). Consecuentemente se produjo la disminución de la superficie plantada en las principales regiones productoras de batata del país, con mermas de rendimientos de las variedades comerciales de mayor importancia. No obstante, en la última década, Argentina viene registrando una leve tendencia en aumento de la superficie plantada (FAOSTAT, 2019). En Corrientes la superficie implantada también ha sufrido una disminución importante con una superficie que ronda las 350 has, con rendimientos promedios que están alrededor de las $14.8 \mathrm{tn} \mathrm{ha}^{-1}$ (Araujo et al. (2019). La infección durante el ciclo de cultivo se produce mediante insectos vectores: pulgones y moscas blancas. La propagación vegetativa de la especie conduce a un incremento en la concentración de partículas virales y a su perpetuación en los tejidos vegetales, en perjuicio de los rendimientos (Loebenstein et al., 2009). Para mitigar los efectos de estas enfermedades debe usarse material de propagación agámico de sanidad controlada, multiplicado a partir de semilla básica o fundación, obtenido, a su vez, mediante micropropagación in vitro de meristemas y termoterapia. La multiplicación masiva se realiza a través de viveros multiplicadores en las diferentes zonas productoras del país (Di Feo, 2015). En 2017 el Ministerio de Producción de Corrientes, creó el Proyecto Multiplicación de Batata con Sanidad Controlada, mediante el cual puso en funcionamiento el Vivero Hortícola del Centro Tecnológico de Producción (CE.TE.PRO.), financiado por el Fondo de Desarrollo Rural (FDR) y administrado por la Fundación Correntina de Sanidad Vegetal (FUCOSAVE). Las plantas madres se adquieren en el Instituto de Patología Vegetal del Centro de Investigaciones Agropecuarias del Instituto Nacional de Tecnología Agropecuaria. (IPAVE-CIAPINTA), Córdoba. Actualmente el vivero multiplica catorce cultivares. La macropropagación se realiza en el CE.TE.PRO. bajo invernaderos que cumplen con el protocolo sanitario establecido. La producción obtenida se destina principalmente a productores comerciales beneficiarios del Proyecto, los cuales realizan el cultivo bajo normas previamente estipuladas. Como estrategia se realizan capacitaciones teórico prácticas en el campo de productores modelo, mediante la utilización de parcelas demostrativas, donde se encuentran emplazados los núcleos semilleros. En estos últimos se plantan los esquejes saneados, a partir de los cuales se obtiene material de propagación para lotes comerciales. Los núcleos se encuentran protegidos con malla anti-insecto tipo microtúnel o jaula. El Vivero Hortícola Provincial reemplaza anualmente la totalidad de sus plantas madres y en los núcleos semilleros cada uno o dos años. El recurso humano para ejecutar el mismo consta de un ingeniero agrónomo responsable del proyecto y un técnico de campo.

El objetivo de este proyecto es recuperar y mejorar la actual situación del cultivo en la provincia, pudiendo alcanzar la totalidad de productores comerciales. Reemplazar paulatinamente con material saneado todas las cuencas batateras, y así recuperar la superficie y calidad de producción. Este es un desafío que se planteó el Ministerio de Producción poniendo en valor ésta importante economía regional de la pequeña y mediana escala de productores. Teniendo en cuenta las innumerables ventajas competitivas de este cultivo, ya sea para consumo humano en fresco e industrializado, consumo animal y la potencialidad como biocombustible.

\section{METODOLOGÍA}

\section{Vivero de multiplicación}

El Proyecto puede dividirse en dos etapas. La primera es la que se desarrolla íntegramente en el Vivero Hortícola del CE.TE.PRO. cuyo objetivo es la multiplicación de material saneado. La segunda etapa se desarrolla en el campo del productor y va desde la construcción de núcleos semilleros hasta la implantación de lotes comerciales demostrativos y capacitaciones.

Todos los años se reemplaza la totalidad de las plantas con material saneado nuevo. Generalmente esta práctica se realiza en otoño para poder contar con guías saneadas y entregar al productor batatero en la primavera 
siguiente, en la época de plantación a campo.

El vivero actualmente cuenta con $884 \mathrm{~m}^{2}$ de superficie cubierta, construido por dos macrotúneles para el proceso de adaptación y rustificación y 4 módulos de invernadero para la obtención de guías. Ambos tipos de estructura poseen antecámaras con doble puerta de acceso provistas de malla anti-insecto de 50 Grados Mesh y pediluvio para la desinfección. Las aberturas laterales y cenitales se encuentran también cubiertas con la misma malla. anti-insecto.

En una primera instancia se recibe una pequeña cantidad de plantines saneados de diferentes cultivares y se los trasplanta en los macrotúneles para aumentar la cantidad de material vegetal. El marco de plantación es de $0.25 \mathrm{~m}$ entre plantas por 1,5 m entre líneos. De allí se obtienen guías que son plantadas en los invernaderos.

En los invernaderos, el distanciamiento es mayor: 0,5 metros entre plantas y 1,5 metros entre líneos. Las plantas se conducen en espalderas, dejando solo un tallo principal tutorado con hilo cinta. Tanto en los macrotúneles como en los invernaderos se planta en lomos con riego por goteo y mulching plástico negro de 25 micrones de espesor. Todas las estructuras poseen sistema de riego por aspersión. Éste cumple la función de bajar la temperatura en épocas estivales y aumentar la humedad relativa para combatir ácaros en época de sequía.

Para la detección de plagas transmisoras de virus se utilizan trampas amarillas y se realizan monitoreos diarios. Realizándose aplicaciones preventivas semanales de fungicidas e insecticidas.

Para conservar el material cortado hasta el momento de la entrega al productor se utiliza una plantinera ubicada dentro de los invernaderos, con sustrato preparado con $50 \%$ de arena desinfectada con agua hervida y $50 \%$ de sustrato profesional, GROWMIX MultiPro ${ }^{\circledR}$ que contiene Turba de musgo Sphagnum de fibras medias, compost de corteza, cal calcita, cal dolomita y agentes humectantes.

Las guías son porciones de tallo apical y sub apical de entre 30 y 40 centímetros de largo y 6 a 10 nudos. En el caso de que estén enraizadas se denominan plantines. Estas guías son entregadas al productor para ser plantadas en un núcleo semillero.

\section{Núcleos semilleros}

Un núcleo semillero de batata es una estructura fija instalada en el campo de un productor, protegida con malla anti-insecto de 50 Grados Mesh, que contiene plantas de batata saneadas, de donde el productor se proveerá de guías para iniciar un cultivo comercial durante un periodo de 1 a 3 años. Pueden ser Jaulas o Microtúneles.

\section{Elección del lugar}

El núcleo semillero será instalado en la chacra del productor en un terreno alto de buen escurrimiento y drenaje, evitando de esta forma posibles encharcamiento o anegamiento. Debe estar cerca de una fuente de agua para suministrar riego de ser necesario. Debe encontrarse cerca y accesible, de modo que facilite su monitoreo frecuente, dos veces por semana, por ejemplo y estar protegido del ingreso de animales que puedan dañar la estructura (gallinas, perros, vacas, caballos etc.).

\section{Procedimiento para la construcción de núcleos semilleros de tipo Microtúneles de $25 \mathbf{m}^{2}$}

Remoción de suelo: Luego de elegir el lugar se procede a remover el suelo con pala a una profundidad de 0,25 metros como mínimo. Se trabaja en un ancho de 1,5 metros por 25 metros de largo. Esta remoción de suelo puede realizarse en forma manual utilizando herramientas de mano como una pala o se puede realizar en forma mecánica con el pasaje de rastra de disco o motocultor según disponibilidad. Se recomienda para favorecer el crecimiento de las raíces el uso de fertilizantes ricos en fosforo.

Construcción del tablón, hoyado y plantación: con el suelo bien mullido y fertilizado se construye un cantero con azada de 1 metro de ancho por 25 metros de largo. La altura del tablón debe ser como mínimo de 0,20 metros. Finalmente se marcan los líneos de plantación con la ayuda de estacas e hilo de nylon. El marco de plantación es de 0,25 metros entre plantas por 0,25 metros entre líneos. Una vez marcados los líneos se realiza el hoyado. Esta tarea se puede realizar tanto con pala como con un hoyador de madera de punta cónica. Las guías deben ser enterradas hasta la mitad o al menos 4 nudos para garantizar su enraizamiento dejando en super- 
ficie al menos 2 nudos para que se desarrollen los tallos y hojas. Es importante realizar suficiente presión para asegurar el contacto con el suelo. Posteriormente aplicar el riego de asiento con aproximadamente $500 \mathrm{cc}$ de agua por planta para eliminar el aire y garantizar la humedad. Para un núcleo de 25 metros son necesarias 400 guías. La ramificación de las mismas comienza a los 15 días aproximadamente, dependiendo de la época del año. Esta se verá favorecida por las altas temperaturas y humedad. La primera cosecha de guías se realiza a los 30 días posteriores a la plantación. La productividad del núcleo es de 175 a 200 guías por m².

Armado del túnel: Para construir un túnel de 25 metros es necesario contar con 26 varillas flexibles de 2,2 metros de longitud. Las mismas pueden ser de tacuara (Guadua angustifolia o Guadua spp) o bien de hierro de construcción de $4,2 \mathrm{~mm}$ forrados con cintas de goteo en desuso. Se ubican las varillas distanciándolas a $1 \mathrm{~m}$ y se entierran los extremos formando un arco. Posteriormente se colocan dos estacas en los extremos del túnel distanciadas a $1 \mathrm{~m}$ para tensar la malla anti-insecto. Esto dará rigidez a la estructura. Finalmente se corta la malla a medida y se entierran los bordes en todo su perímetro para evitar que ingresen insectos.

Las guías obtenidas del núcleo semillero son plantadas en Módulos productivos o bien en lotes semilleros.

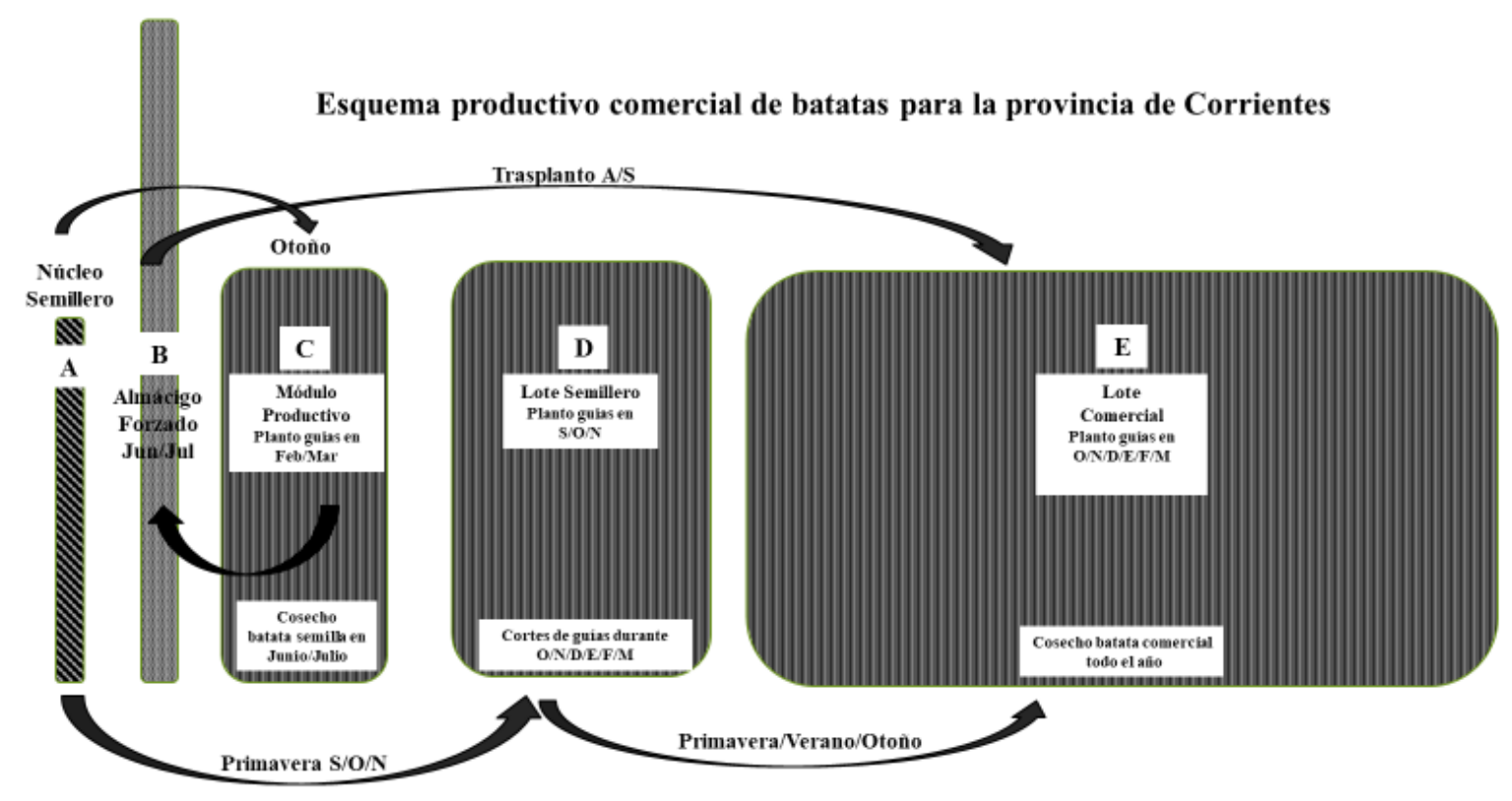

Figura 1. Esquema productivo de batatas para la provincia de Corrientes. A: núcleo semillero. B: almácigo forzado. C: módulo productivo. D: lote semillero y E: lote comercial.

\section{Lotes semilleros}

El Lote semillero es un cultivo de batata, realizado con guías saneadas provenientes de un núcleo semillero o bien de un Vivero de Multiplicación, cuyo principal objetivo es obtener guías para un Lote Comercial. El marco de plantación puede ser convencional, por ejemplo $0,3 \mathrm{~m}$ entre plantas por $1 \mathrm{~m}$ entre líneos. Estos se plantan en lugares alejados, al menos a 250 metros de un lote comercial o bien protegidos con alguna barrera vegetal (cortina de árboles o cultivo de maíz). Debe ser monitoreado dos veces por semana y mantener el cultivo libre de enfermedades y plagas transmisoras de virus, aplicando insecticidas de ser necesario. La época de plantación de un lote semillero se inicia cuando finaliza el peligro de heladas. Los cortes de guías se realizan durante todo el periodo primavero-estival (Figura 1). La tasa reproductiva, utilizando solo los extremos apicales, es de 1:10.

No se recomienda dejar que el lote semillero pase el invierno para cosechar las guías, éste puede actuar como hospedero de insectos plaga muy perjudiciales y de difícil manejo como son los Coleópteros. Una práctica cultural aconsejable es la rotación de cultivos con maíz o porotos, y el control químico de rebrotes de batata. 
González, C.A. et al.: Batata con sanidad controlada.

\section{Módulos productivos}

Un módulo productivo es un cultivo de batata realizado con guías saneadas obtenidas de un núcleo semillero o bien del Vivero de Multiplicación, cuyo único objetivo es la obtención de batata semilla para la siembra de un almácigo forzado en invierno. Debe ser manejado de la misma manera que los lotes semilleros. La época de plantación es fin de verano- principio de otoño (Figura 1). La cosecha se realiza una semana antes de la probable ocurrencia de la primera helada. La productividad utilizando una densidad de $33.333 \mathrm{pl} \mathrm{ha}^{-1}$ es de 15 tn ha de batata semilla.

\section{Almácigos forzados}

Antes de la ocurrencia de la primera helada se cosechan las batatas del módulo productivo y se construyen los almácigos forzados.

Los almácigos forzados son tablones realizados en invierno, sembrados con batata semilla saneada, obtenida de los módulos productivos, protegidos con túneles de polietileno de 50 o 100 micrones. De allí se obtienen plantines para ser trasplantados a un lote comercial.

Para construir el almácigo se procede de la misma forma que en los núcleos semilleros. Una vez que el suelo está bien mullido y fertilizado se ubican las batatas en el tablón diferenciadas por categoría. Las medianas (entre 150 y $450 \mathrm{~g}$ ) por un lado y las pequeñas (entre 60 y $150 \mathrm{~g}$ ) por otro. Estas deben estar enteras, sanas, sin rajaduras, ni deformaciones. Deben ser tratadas con una solución insecticida fungicida y dejar orear. Luego se tapan con una pequeña capa de tierra de $0,03 \mathrm{~m}$ de espesor. Finalmente se cubre con polietileno formando un túnel. Al cabo de 20 días aproximadamente dependiendo del cultivar las batatas comienzan a brotar. Es fundamental el deshierbe manual, la aireación y el control de la humedad. Son de especial atención las enfermedades asociadas al complejo de hongos de suelo. La extracción de plantines se realiza a los 60 días desde la siembra aproximadamente, cuando los plantines tienen $0,25 \mathrm{~m}$ de longitud y 6 hojas. Un almacigo forzado a cielo abierto cubierto con polietileno de 50 micrones tiene una productividad de 500 plantines. $\mathrm{m}^{-2}$, producidas en tres camadas. Otra opción de cosecha de material para la plantación es realizando un corte a $0,05 \mathrm{~m}$ de la superficie extrayendo guías sin raíces. Dejando un pequeño tallo para la siguiente brotación. Esto tiene como ventaja que no se transporta suelo del almácigo a los lotes comerciales. También disminuye la posibilidad de trasladar material con insectos barrenadores.

\section{Lote Comercial}

La estrategia de transferencia tecnológica del proyecto consiste en la realización de parcelas demostrativas comerciales. Estas se llevan a cabo íntegramente en el campo de un productor seleccionado. Se implanta el cultivo acompañando al productor en cada paso del modelo propuesto y utilizando un paquete tecnológico que como mínimo debe incluir: material saneado, fertilización ajustada a un análisis de suelo y manejo integrado de plagas, enfermedades y malezas.

Las épocas de plantación sugeridas son: tempranas: fines de agosto y septiembre, con riesgos de heladas. De estación: octubre-noviembre. Tardías: diciembre y enero, con alto porcentaje de fallas por altas temperaturas y sequía, por lo que se recomienda riego. Extra tardías: febrero - marzo, con menores rendimientos y peligro de heladas tempranas (Figura 1). Los rendimientos obtenidos en parcelas demostrativas son variables y dependieron del cultivar utilizado y las condiciones agroecológicas. En todos los casos han superado las 30 tn $\mathrm{ha}^{-1}$ con máximos de 63 tn ha ${ }^{-1}$.

\section{RESULTADOS OBTENIDOS}

Se han entregado más de 50.000 guías saneadas a productores e instituciones como: Asociaciones de productores, INTA Misiones, Escuelas de la familia Agrícola (EFAS), Escuelas Agrotécnicas y Fundaciones. Se han realizado 2000 metros cuadrados de núcleos semilleros en las localidades de: Tres de Abril, Colonia Pando, San Miguel, Colonia Tatacuá, Colonia San Antonio, Alvear, Virasoro, Colonia Unión, La Cruz, Saladas, Pedro Fernández, Riachuelo, Santa Ana, San Cayetano, Mercedes, Esquina, Pago de los Deseos, Colonia Cabral, San Luis del Palmar, Capital. Con un impacto directo sobre 200 hectáreas. Se han entregado guías sanea- 
das a Provincias vecinas como Chaco, Santa Fe, Entre Ríos y Misiones. Se realizaron 10 Capacitaciones en el interior de la Provincia y CE.TE.PRO. y una virtual con más de 100 participantes de diferentes provincias. Desde el inicio del proyecto se han realizado en todo el periodo 10 parcelas demostrativas. Actualmente se asesoran a 30 productores y 5 Efas/Agrotécnicas.

\section{CONSIDERACIONES FINALES}

El cultivo de Batata, tiene un gran potencial. Los últimos tiempos han demostrado que con la incorporación de tecnología se puede no sólo recuperar la productividad perdida, sino promover nuevas variedades de alta demanda a nivel mundial. Permite generar una alternativa de producción, por tener varias cosechas al año, con importantes ingresos. Nuestra Provincia tiene el gran desafío de mecanizar la actividad para encarar modelos económicos sustentables, para los que son necesarios programas de desarrollo con líneas de asistencia financiera y promoción de la actividad, que impulse a productores a modelos empresariales.

\section{BIBLIOGRAFÍA}

Araujo, J. O., Carballo, M. S., Lezcano, R. P., Mambrin, A. G., Picolini, P. E., Pinto Ruíz, G. A. Roncaglia, L. M., Solís, V. E. (2019). Recuperación y desarrollo productivo de los cultivos de batata y mandioca en la provincia de Corrientes. Consejo Federal de Inversiones. Ministerio de Producción de Corrientes. Informe Final. Disponible en: http://biblioteca.cfi.org.ar/documento/recuperacion-ydesarrollo-productivo-de-los-cultivos-de-batata-y-mandioca-en-la-provincia-de-corrientes/. Último acceso: 5 de agosto del 2020.

Di Feo, L. D. V. (2015). Producción, multiplicación y manejo de propágulos de batata de sanidad controlada. Córdoba, Argentina. Secretaría de Ciencia y Tecnología. Ministerio De Industria, Comercio y Desarrollo Científico Tecnológico. Gobierno de la Provincia De Córdoba. Disponible en: https:// www.researchgate.net/

publica-

tion/288503472_Produccion_multiplicacion_y manejo de propagulos de batata de sanidad control ada_Liliana_del_Valle_Di_Feo. Último acceso 8 de agosto de 2020.

Fajardo, J., Lutaladio, N. B., Larinde, M., Rosell, C. Barker, I., Roca, W., and Chujoy, E. (2007). Quality declared planting material. Protocols and standards for vegetatively propagated crops. Fao plant production and protection paper 195. International Potato Center (CIP). Lima Perú. Disponible en: http:// www.fao.org/3/a-i1195e.pdf. Último acceso 8 de agosto de 2020.

FAOSTAT. (2019). Food and Agriculture Organization of the United Nations. Disponible en: http:// www.fao.org/faostat/en/\#data/QC/visualize Fecha última consulta: 4 de junio del 2020.

Huamán, Z. (1992). Botánica sistemática y mor fología de la planta de batata o camote. Boletín de Información Técnica 25, Centro Internacional de la Papa, Lima, Perú. Disponible en: https:// books.google.es/books? id=hIkspoOH9NMC\&printsec $=$ frontcover\&hl=es\&source=gbs_ge summary $r \& c a d=0 \# v=0$ onepage\&q \&f=false. Último acceso 8 de agosto de 2020.

Loebenstein G, Thottappilly G, Fuentes S, Cohen J. (2009). Virus and Phytoplasma Diseases. En: Loebenstein G and Thottappilly G. The Sweet Potato: 105-131. 